\title{
Colloidal stability of polymeric nanoparticles in biological fluids
}

\author{
Stefano Lazzari • Davide Moscatelli • \\ Fabio Codari - Mario Salmona · \\ Massimo Morbidelli • Luisa Diomede
}

Received: 3 August 2011/Accepted: 10 May 2012/Published online: 6 June 2012

(C) Springer Science+Business Media B.V. 2012

\begin{abstract}
Estimating the colloidal stability of polymeric nanoparticles (NPs) in biological environments is critical for designing optimal preparations and to clarify the fate of these devices after administration. To characterize and quantify the physical stability of nanodevices suitable for biomedical applications, spherical NPs composed of poly-lactic acid (PLA) and poly-methyl-methacrylate (PMMA), in the range 100-200 nm, were prepared. Their stability in salt solutions, biological fluids, serum and tissue homogenates was analyzed by dynamic light scattering (DLS). The PMMA NPs remained stable in all fluids, while PLA NPs aggregated in gastric juice and spleen homogenate. The proposed stability test is therefore useful to see in advance whether NPs might aggregate when administered in vivo. To assess colloidal stability ex vivo as well, spectrophotofluorimetric
\end{abstract}

S. Lazzari · F. Codari · M. Morbidelli

Department of Chemistry and Applied Biosciences, Institute for Chemical and Bioengineering, ETH Zurich, 8093 Zurich, Switzerland

D. Moscatelli ( $\square$ )

Dipartimento di Chimica, Materiali e Ingegneria Chimica "Giulio Natta", Politecnico di Milano, 20131 Milan, Italy e-mail: davide.moscatelli@polimi.it

M. Salmona · L. Diomede

Department of Molecular Biochemistry and

Pharmacology, Istituto di Ricerche Farmacologiche

“Mario Negri”, Via La Masa 19, 20156 Milan, Italy analysis was employed, giving comparable results to DLS.

Keywords Nanoparticles · Poly-lactic acid · Poly-methyl-methacrylate $\cdot$ Nanomedicine . Gastrointestinal fluids $\cdot$ Serum $\cdot$ Homogenates
Abbreviations
NPs Nanoparticles
DLS Dynamic light scattering
PLA Poly-lactic acid
PMMA Poly-methyl-methacrylate
$\mathrm{Sn}(\mathrm{Oct})_{2} \quad$ 2-Ethylhexanoic acid tin(II) salt
LT S,S-3,6-Dimethyl-1,4-dioxane-2,5-dione
SEC Size exclusion chromatography
THF Tetrahydrofuran
TEM Transmission electron microscopy
SEM Scanning electron microscopy
FI Fluorescence intensity
HPLC High pressure liquid chromatography
PSD Particle size distribution

\section{Introduction}

Parenteral and oral administrations are the most common delivery routes used for pharmaceuticals. Parenteral delivery allows direct administration of the drug to the whole cardiovascular system, while oral administration ensures better compliance as it is less 
invasive. However, the different $\mathrm{pH}$ and enzyme-rich gastric fluids encountered by the drug in the gastrointestinal tract, as well as the limited drug absorption due to the gastrointestinal barrier, strongly limit this administration route. Whichever route is chosen, the development of molecules for the treatment of diseases with unfavorable prognosis is often limited by drug bioavailability, rapid clearance, difficulty crossing biological barriers and-last but not leastby severe side effects. To overcome these hurdles, the use of biocompatible drug-loaded nanoparticles (NPs) has been proposed (Alexis et al. 2008).

Polymeric NPs are an innovative generation of nanovectors with great potential as drug carriers and tracking devices for targeted delivery to specific sites (Riehemann et al. 2009). They improve the gastric stability of therapeutics (Mohs et al. 2009) suggesting that they could be employed for oral drug delivery (Kuentz 2008). These nanoformulations may also favor the transport of drugs across the mucosal barrier, promoting their entry into the circulation (Win and Feng 2005).

Introducing such devices for a more effective drug delivery involves new problems, however, such as NP stability, drug release mechanisms, and NP interactions with the mononuclear phagocytes in the bloodstream, directly after injection or after crossing the gastrointestinal barrier. While the interaction of NPs with serum proteins has been investigated (Aggarwal et al. 2009), with particular attention to opsonization, and many theories have been proposed concerning the release mechanisms (Arifin et al. 2006), the stability of NPs in biological fluids has not been fully characterized. It is essential to understand whether and how the different body environments influence NP stability, to design optimal nanoformulations, and to identify their fate after administration.

In general, nanoformulation stability is classified in terms of chemical stability (i.e., the chemical degradation of the polymeric NPs), long-term "pharmaceutical stability" (i.e., the changes in the quality of a drug in time under the influence of environmental factors) (Muthu and Feng 2009), and physical or colloidal stability. While the long-term "pharmaceutical stability" (Muthu and Feng 2009) and chemical stability have been assessed (Lemoine et al. 1996; Avgoustakis et al. 2002), and different degradation mechanisms have been identified depending on NPs dimensions and polymer reactivity (von Burkersroda et al. 2002), the colloidal stability still remains poorly investigated (Win and Feng 2005; Ruenraroengsak et al. 2010; Madlova et al. 2009).

The aim of this study is to shed light on the physical stability of NPs for biomedical applications, stressing the need for in vitro/ex vivo testing of their stability, before in vivo studies are performed. Measuring the NPs size distribution in time by dynamic laser light scattering (DLS), the formation of aggregates in different biological fluids was monitored. As ex vivo stability is also needed, spectrophotofluorimetric (SPF) analysis was used and its ability to predict NP stability was qualitatively checked by comparison with DLS data.

Poly-lactic acid (PLA) and poly-methyl-methacrylate (PMMA) were selected as prototypes for NP preparations, since both polymers are biocompatible and approved by the US Food and Drug administration (Oh 2011; Squire et al. 2008). Their use permits a comparison of a hydrolytically degradable material, PLA, and a non-degradable one, PMMA (Devalapally et al. 2007; Kumari et al. 2010; Cui et al. 2009; Prokop and Davidson 2008). The stability of these polymer NPs was investigated in the stock solutions usually adopted for their storage and in biological fluids mimicking the environments they meet after administration. In particular, saliva, gastric juice, intestinal fluid, lysosomal fluid, serum and tissue homogenates were examined.

\section{Materials and methods}

\section{Materials}

2-Ethylhexanoic acid tin(II) salt $\left(\mathrm{Sn}(\mathrm{Oct})_{2}\right)$, polystyrene standards from 500 to $2,000,000 \mathrm{Da}$ and 3,6dimethyl-1,4-dioxane-2,5-dione (D,L-lactide, LT, further recrystallized in extra dried Toulene puriss) were purchased from Sigma Aldrich (Buchs, Switzerland). Toluene was obtained from Riedel-de Haen (Basel, Switzerland). Methyl methacrylate, tetrahydrofuran (THF), cyclohexane, potassium peroxydisulfate, Tween ${ }^{\circledR} 80$, dextrose alpha-D-(+)-glucose anhydrous, sodium hydrogen carbonate, 1-dodecanol, HPLC grade acetonitrile and orthophosphoric acid, sodium DL-lactate and pepsin from porcine gastric mucosa were purchased from Fluka-Chemie AG (Germany). Dichloromethane and Rhodamine B base were purchased from Acros Organics (Basel, Switzerland). 
Cholesteryl Bodipy ${ }^{\circledR}$ was obtained from molecular probes (Milan, Italy).

Synthesis of NPs

PLA was synthesized by ring opening polymerization of LT according to Yu et al. (2009). The reaction was carried out at $130{ }^{\circ} \mathrm{C}$ for $3 \mathrm{~h}$ in order to limit side reactions such as trans-esterification and cyclization. $\mathrm{Sn}(\mathrm{Oct})_{2}$ was used as catalyst and DL-lactic acid as cocatalyst. In a first step, $25 \mathrm{~g}$ of LT were melted at $100{ }^{\circ} \mathrm{C}$ using an oil bath in a stirred, round-bottomed, one-neck $100 \mathrm{~mL}$ reactor flask. Then, 70 and $30 \mathrm{mg}$ of catalyst and co-catalyst, respectively, were added and the temperature was raised up to reaction condition. After reaction, the polymer was dissolved in dichloromethane and precipitated in cyclohexane in order to remove residual monomer and impurities such as cyclic compounds. After purification, the polymer was dried in vacuum at 250 mbar at $25{ }^{\circ} \mathrm{C}$ and characterized by size exclusion chromatography (SEC).

NPs of PLA loaded with Cholesteryl Bodipy ${ }^{\circledR}$ were produced by flash nanoprecipitation (Liu et al. 2008). In brief, a THF solution of $1 \%(\mathrm{w} / \mathrm{v})$ PLA and $0.001 \%(\mathrm{w} / \mathrm{v})$ Cholesteryl Bodipy ${ }^{\circledR}$ was mixed in a $0.1 \%(\mathrm{w} / \mathrm{v})$ Tween ${ }^{\circledR} 80$ distilled water solution, using a 4-inlet vortex mixer in which the streams were tangentially mixed (Liu et al. 2008). Altering streams of distilled water and THF, at flow rates of 100 and $10 \mathrm{~mL} / \mathrm{min}$, respectively, were employed. THF was removed by evaporation at 125 mbar at room temperature for $6 \mathrm{~h}$. The residual THF was quantified by gas chromatographic analysis, as described in "Gas chromatography" section. The Tween ${ }^{\circledR} 80$ concentration in the PLA NPS suspension was then adjusted to $0.25 \%(\mathrm{w} / \mathrm{v})$ in order to reach the same concentrations of Tween ${ }^{\circledR} 80$ and PMMA. NPs were characterized by TEM and DLS.

PMMA NPs loaded with Rhodamine B base were prepared by emulsion polymerization. In brief, a solution containing $2 \%(\mathrm{w} / \mathrm{v})$ of methyl methacrylate, $0.02 \%(\mathrm{w} / \mathrm{v})$ of Rhodamine $\mathrm{B}$ base, and $5 \%$ of Tween ${ }^{\circledR} 80$ was kept under magnetic stirring at $80{ }^{\circ} \mathrm{C}$. Then, $0.05 \%(\mathrm{w} / \mathrm{v})$ of potassium peroxydisulfate was added and the reaction was carried out for $4 \mathrm{~h}$. The PMMA NPS were then diluted 1:20 (v/v) in water to obtain a suspension with the same particle and Tween ${ }^{\circledR} 80$ concentration as the PLA ones. PMMA molecular weight was characterized by SEC (after centrifugation of the NPs at $16,000 \times g$ for $10 \mathrm{~min}$ ) and particle size and morphology were investigated by DLS and SEM.

Size exclusion chromatography (SEC)

The molecular weight distribution of PMMA and PLA was characterized by SEC (Agilent, 1100 series) equipped with ultraviolet and differential refractive index detectors. A pre-column and two PLgel $5 \mu \mathrm{m}$ MIXED-C columns (Polymer Laboratories, length $300 \mathrm{~mm}$ and diameter $7.5 \mathrm{~mm}$, measuring range 2,000-2,000,000 Da) were employed. Chloroform was used as eluent at a flow rate of $1 \mathrm{~mL} / \mathrm{min}$ and the temperature was set at $30{ }^{\circ} \mathrm{C}$. The polymer was dissolved in chloroform employing a concentration of $1 \mathrm{mg} / \mathrm{mL}$. Universal calibration was applied, based on poly(styrene) standards, adopting the Mark-Houwink constants for P(DL)LA. (Yu et al. 2009).

\section{Gas chromatography}

Gas chromatography was employed to verify the complete removal of THF from the PLA latex. A Hewlett-Packard gas chromatograph HP6890 apparatus was used, equipped with a (crosslinked $5 \% \mathrm{PH}$ ME Siloxane) $30 \mathrm{~m} \times 0.3 \mathrm{~mm} \times 0.25 \mu \mathrm{m}$ (USA) HP column and TCD detector. Helium was used as carrier gas at a flow rate of $10 \mathrm{~mL} / \mathrm{min}$. The samples were injected as prepared after nanoprecipitation. The injection and detector temperature were $250{ }^{\circ} \mathrm{C}$ and the column temperature was raised from 60 to $250{ }^{\circ} \mathrm{C}$. THF water mixtures with a known amount of THF were injected for calibration.

\section{Dynamic laser light scattering (DLS)}

NPs size was measured by DLS at $37{ }^{\circ} \mathrm{C}$ performed with a Zeta Nano ZN (Malvern Instruments, UK). Each cuvette was filled with NP suspensions and the different solutions (stock solutions, gastrointestinal fluids, serum and tissue homogenates) in a 1:1 (v/v) ratio. In other words, the DLS analysis was performed with a concentration of $5 \times 10^{-4}(\mathrm{v} / \mathrm{v})$. Multiple scattering was ruled out by performing analysis in more dilute conditions (up to $5 \times 10^{-6} \mathrm{v} / \mathrm{v}$ ) which gave the same result. The data are the average of three runs of the same sample where the standard deviation (SD) was always below $5 \%$. 
Transmission electron microscopy (TEM)

To evaluate the PLA NP size and morphology, one drop of the NP suspension was diluted in $10 \mathrm{~mL}$ water and $40 \mu \mathrm{L}$ of this solution were deposited on a copper grid (400 mesh) previously covered with a $8 \mathrm{~nm}$ thick carbon layer. After $30 \mathrm{~s}$, the droplet was removed and images of the slices were taken with a FEI Morgagni 268 transmission electron microscope (FEI Company, USA).

High performance liquid chromatography (HPLC)

PLA degradation was evaluated by means of an HPLC apparatus (1200 series, Agilent) equipped with a C18 column $(3.9 \mathrm{~mm} \times 150 \mathrm{~mm}$, particle size $3.5 \mu \mathrm{m}$, Eclipse XDB, Agilent) and an ultraviolet detector $(210 \mathrm{~nm})$. Water and acetonitrile, acidified with $0.1 \%$ (v/v) phosphoric acid, were used as mobile phases (flow rate $1 \mathrm{~mL} / \mathrm{min}$ ) to quantify the lactic acid (Codari et al. 2010) After precipitation of the NPs via centrifugation at $13,000 \times g$, the supernatant was recovered and injected as such in the HPLC.

\section{SPF analysis}

SPF analysis was performed to investigate the colloidal stability over time. PLA and PMMA NPs were diluted 1:1 (v/v) with the different stock solutions, gastrointestinal fluids, serum and tissue homogenates and incubated at $37^{\circ} \mathrm{C}$ for different times. The fluorescence intensities (FI) of the suspensions were determined every $10 \mathrm{~min}$ for $60 \mathrm{~h}$, using a spectrophotofluorimeter (EnSpire ${ }^{\mathrm{TM}}$ Multilabel Plate Reader, Perkin Elmer, USA) at $\lambda_{\mathrm{exc}}=481 \mathrm{~nm}$ and $\lambda_{\mathrm{em}}=$ $512 \mathrm{~nm}$ for cholesteryl Bodipy ${ }^{\circledR}$ and at $\lambda_{\text {exc }}=548 \mathrm{~nm}$ and $\lambda_{\mathrm{em}}=575 \mathrm{~nm}$ for Rhodamine $\mathrm{B}$ base. All the experiments were run in triplicate in Corning ${ }^{\circledR}$ 96-well plates. Data are expressed as scaled values with respect to their initial value and as averages of the three runs. The SD among the samples was always lower than $5 \%$, so it was omitted from the graphs.

Stock solutions and biological fluids

The NPs were incubated in stock solutions, gastrointestinal fluids, and tissue homogenates. The following stock solutions were used: distilled water, $5 \mathrm{mM}$ phosphate buffered saline (PBS) and aqueous
Table 1 Composition of the synthetic biological fluids used to simulate the physicochemical environment of the gastrointestinal tract

\begin{tabular}{|c|c|c|c|c|}
\hline Composition & Saliva & $\begin{array}{l}\text { Gastric } \\
\text { juice }\end{array}$ & $\begin{array}{l}\text { Intestinal } \\
\text { fluid }\end{array}$ & $\begin{array}{l}\text { Lysosomal } \\
\text { fluid }\end{array}$ \\
\hline $\begin{array}{l}\text { Calcium chloride } \\
\text { dihydrate }\end{array}$ & 40.0 & - & - & 0.2 \\
\hline Mucin & 0.1 & - & - & - \\
\hline Potassium chloride & 50.0 & - & - & - \\
\hline Sodium chloride & 70.0 & 300.0 & - & 549.3 \\
\hline $\begin{array}{l}\text { Sodium phosphate } \\
\text { dibasic }\end{array}$ & 40.0 & - & - & 5.0 \\
\hline Urea & 170.0 & - & - & - \\
\hline Pepsin & - & 0.9 & - & - \\
\hline Hydrochloric acid & - & 840.0 & - & - \\
\hline Sodium hydroxide & - & - & - & 1500.4 \\
\hline $\begin{array}{l}\text { Magnesium } \\
\text { chloride } \\
\text { hexahydrate }\end{array}$ & - & - & - & 0.1 \\
\hline Sodium sulfate & - & - & - & 2.7 \\
\hline Citric acid & - & - & - & 1082.7 \\
\hline Glycine & - & - & - & 7.9 \\
\hline $\begin{array}{l}\text { Sodium citrate } \\
\text { tribasic dihydrate }\end{array}$ & - & - & - & 2.6 \\
\hline $\begin{array}{l}\text { Tartaric acid } \\
\text { disodium salt } \\
\text { dihydrate }\end{array}$ & - & - & - & 3.9 \\
\hline Sodium lactate & - & - & - & 7.6 \\
\hline Sodium pyruvate & - & - & - & 7.8 \\
\hline $\begin{array}{l}\text { Sodium hydrogen } \\
\text { carbonate }\end{array}$ & - & - & 800.1 & - \\
\hline $\mathrm{pH}$ & 5.6 & 1.2 & 8.1 & 3.8 \\
\hline
\end{tabular}

Concentrations are reported in $\mathrm{mM}$

solutions of $\mathrm{NaCl}(0.9 \% \mathrm{w} / \mathrm{v})$, and dextrose $(5 \%$ w/v). Simulated gastrointestinal fluids were prepared according to US Pharmacopeia XXIV, 2006 and their composition and $\mathrm{pH}$ are summarized in Table 1. Saliva contained $0.1 \mathrm{mM}$ mucin, and gastric juice $0.9 \mathrm{mM}$ pepsin; intestinal fluid was prepared without pancreatin.

Male CD1 mice, 18-20 g body weight (Charles River Italy, Calco, Como, Italy) were used in order to prepare murine serum and tissue homogenates. Procedures involving animals and their care were conducted in conformity with national and international laws and policies (EEC Council Directive 86609, OJ L358, 1, 12 December 1987; Italian Legislative Decree 116/92, Gazzetta Ufficiale della Repubblica 
Italiana n. 10, 18 February 1992; Guide for the Care and Use of Laboratory Animals, US National Research Council, 1996). Animals were housed at constant temperature $\left(22 \pm 2{ }^{\circ} \mathrm{C}\right)$ and relative humidity $(60 \pm 5 \%)$ and were fed ad libitum with a standard diet. They were then anesthetized and blood was collected from the retroorbital plexus. They were then killed by cervical dislocation and the brain, spleen, and liver was excised. Tissues were homogenized in $5 \mathrm{mM}$ PBS, pH 7.4, in a 1:4 (w/v) ratio and centrifuged at $9,000 \times g$ for $10 \mathrm{~min}$ at $4{ }^{\circ} \mathrm{C}$ (Rizzardini et al. 1998). The supernatant was collected and stored at $-20{ }^{\circ} \mathrm{C}$. Before use, homogenates were diluted 1:10 $(\mathrm{v} / \mathrm{v})$ with distilled water, centrifuged at $1,100 \times g$ for $10 \mathrm{~min}$ at $25^{\circ} \mathrm{C}$, and the supernatant recovered in order to obtain a transparent solution.

\section{Results and discussion}

PLA and PMMA NPs were characterized by DLS in terms of size, polydispersity index and zeta potential. PLA NPs produced by nanoprecipitation showed a larger size and polydispersity than the PMMA ones (Table 2). TEM and SEM analysis showed that PLA and PMMA NPs were spherical and good agreement was found with the DLS results (Fig. 1). Both NP suspensions had a negative zeta potential (Table 2) due to the residual charges of the KPS initiator for PMMA NPs and the dissociation of the carboxylic end groups of the lactic acid for PLA NPs. The larger zeta potential value of the PMMA NPs was confirmed by the higher critical coagulation concentration of the PMMA NPs, which are thus expected to exhibit higher stability. The molecular weight, evaluated by SEC, was 100 and $50 \mathrm{kDa}$ for PMMA and PLA, respectively.

The NPs were incubated at $37{ }^{\circ} \mathrm{C}$ in different stock solutions, gastrointestinal fluids, serum and tissue homogenates in order to study their colloidal stability. The NPs dimension was monitored by DLS over time

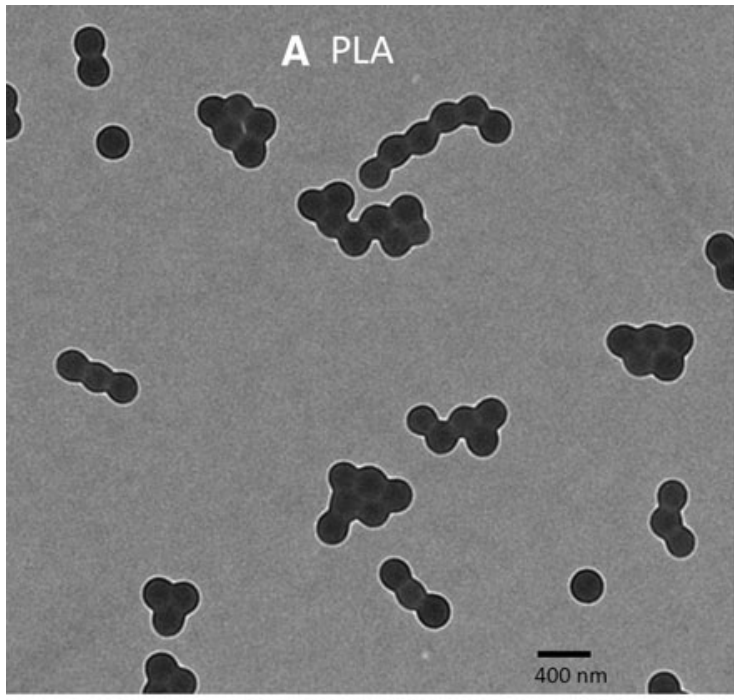

B PMMA

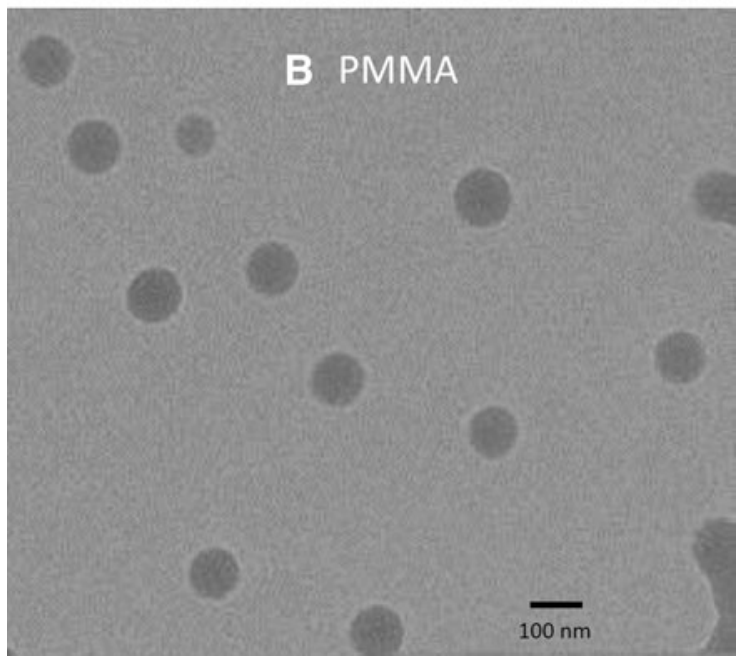

Fig. 1 TEM of PLA NPs (a) and PMMA NPs (b)

to evaluate the occurrence of cluster formation, through aggregation phenomena, which causes a shift of the particle size distribution (PSD) toward higher values. In stock solutions, size distribution did not vary for PLA and PMMA preparations, which thus proved to be stable (Fig. 2a, b) in media in which they are typically stored.

Table 2 Physico-chemical features of fluorescent-loaded polymeric NPs in distilled water

\begin{tabular}{lllll}
\hline Polymer & $\begin{array}{l}\text { z-average } \\
(\mathrm{nm})\end{array}$ & $\begin{array}{l}\text { Polydispersity } \\
\text { index }\end{array}$ & $\begin{array}{l}\text { Zeta potential } \\
(\mathrm{mV})\end{array}$ & $\begin{array}{l}\text { Critical coagulation } \\
\text { concentration }(\mathrm{M})\end{array}$ \\
\hline PLA & $196.0 \pm 0.6$ & $0.173 \pm 0.003$ & $-18.5 \pm 0.9$ & 0.31 \\
PMMA & $95.7 \pm 2.1$ & $0.040 \pm 0.01$ & $-38.4 \pm 2.5$ & 0.43 \\
\hline
\end{tabular}



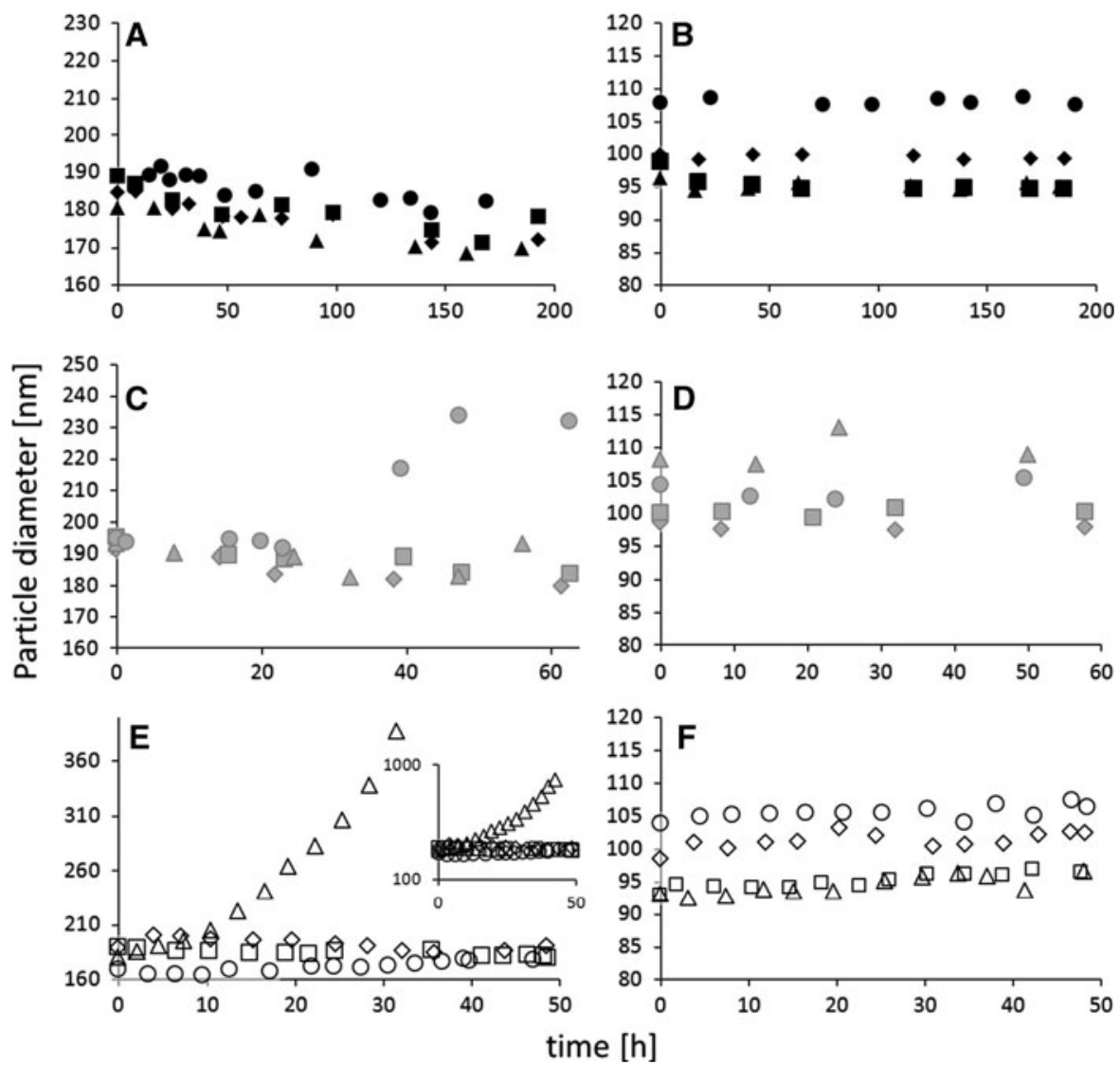

Fig. 2 Effect of biological fluids on particle size-DLS measurements. PLA (a, c, e) and PMMA (b, d, f). Stock solutions: distilled water (filled diamond), PBS (filled square), isotonic (filled triangle), dextrose (filled circle); gastrointestinal fluids: synthetic intestinal fluid (shaded diamond), artificial

The stability of NPs in synthetic gastrointestinal fluids was evaluated for $60 \mathrm{~h}$ to simulate maximum persistence in the gastrointestinal tract after oral administration. To create the different chemical environments of the gastrointestinal tract (i.e., mouth, stomach, and intestine), fluids usually employed to evaluate the stability of drug formulations were prepared as described in the United States Pharmacopeia (US Pharmacopeia XXIV, 2006) (Table 1). No significant change in PSD was observed for PMMA and PLA preparations incubated at $37^{\circ} \mathrm{C}$ with saliva (Fig. 2c, d). In synthetic gastric juice, significant aggregation of PLA NPs began after $24 \mathrm{~h}$ incubation (Fig. 2c), leading to an increase of about $20 \%$ of the mean of the PSD, while PMMA NPs remained stable probably thanks to their higher zeta potential (Fig. 2d). Intestinal stability was investigated by lysosomal fluid (shaded square), saliva (shaded triangle), gastric juice (shaded circle); homogenates: serum (open diamond), brain (open square), spleen (open triangle), liver (open circle)

incubating NPs in artificial intestinal fluid, prepared without pancreatin, and in lysosomal fluid. The PSDs of PLA and PMMA NPs were not affected proving their stability (Fig. 2c, d).

NP stability in serum and tissue homogenates was considered for $48 \mathrm{~h}$ in order to mimic a typical persistence in the body. Homogenates represent the best possibility to get an idea of the effect of the organs or body fluids on the particles.

If NPs aggregate in serum homogenate for instance, this would mean that they could aggregate also upon injection in blood (as serum is a blood component). Not only clots could be formed but also the drug delivery properties of NPs would be affected. On one hand, drug release from single NPs is different than the drug release from a NPs cluster, as the drug has to diffuse throughout different "layers" of particles. On 
the other hand, the NPs residence time in the body would be affected: if NPs are larger than a certain threshold, they are easily uptaken by white cells (He et al. 2010). As shown in Fig. 2e, PLA NPs remained stable in serum, brain, and liver homogenates indicating that the interaction with serum proteins or the presence of hepatic detoxifying enzymes did not alter their physical stability. PLA NPs, however, significantly aggregated in the spleen homogenate after approximately $15-16 \mathrm{~h}$ incubation, forming large clusters of approximately $800 \mathrm{~nm}$ after $48 \mathrm{~h}$. PMMA NPs remained stable in all the homogenates for the whole analysis (Fig. 2f) due to their higher zeta potential.

More than on the reasons leading to aggregation, connected to the complex environment regulated by enzymes, salts, and $\mathrm{pH}$, focus should be set on the fact that NPs underwent aggregation in some cases. This clearly shows that the proposed systematic in vitro/ex vivo stability test is essential when dealing with new drug delivery nanoformulations: for any new NP preparation designed for in vivo studies, the colloidal stability should be assessed before in vivo experiments are realized, in order to avoid dangerous aftermath due to aggregates or clots formation. To perform different ex vivo studies as the one of this study, in which the samples were quite diluted, DLS may not be adopted because of the samples' opacity and the presence of various other particulate substances, similar in size to the NPs. As in in vivo studies, spectrophotofluorimetry is commonly employed to evaluate the NP biodistribution, a correlation between NP fluorescence and colloidal stability was investigated.

For this purpose, fluorescent probes were loaded into the NPs. For PLA, cholesteryl Bodipy ${ }^{\circledR}$ was chosen for its high hydrophobicity, an important issue when dealing with nanoprecipitation (Fessi et al. 1989; Mora-Huertas et al. 2010). The same dye could not be employed for the PMMA formulation, as it is not resistant to radical exposure, for this reason Rhodamine B base was selected.

It must be kept in mind that polymer degradation and dye release can significantly bias the SPF analysis, while this was not an issue with DLS. Considering though that PMMA is non-degradable, only PLA degradation driven by hydrolysis under biological conditions could influence the analysis. Thus, the chemical stability of PLA NPs was considered analyzing the released amount of lactic acid by
Table 3 Lactic acid release from PLA NPs after 14 days of incubation with different salt solutions

\begin{tabular}{lrl}
\hline Solution & $\begin{array}{l}\text { Lactic acid } \\
(\mathrm{ppm})\end{array}$ & $\begin{array}{l}\text { PLA converted to } \\
\text { lactic acid (\%) }\end{array}$ \\
\hline Water & $8 \pm 2$ & $1.6 \pm 0.4$ \\
$0.9 \%$ Sodium chloride & $12 \pm 3$ & $2.4 \pm 0.6$ \\
$5 \%$ Dextrose & $12 \pm 2$ & $2.4 \pm 0.4$ \\
5 mM Phosphate & $19 \pm 4$ & $3.8 \pm 0.8$ \\
$\quad$ buffered solution, pH 7.4 & & \\
\hline
\end{tabular}

reversed phase chromatography. (Codari et al. 2010) In the first 7 days, no PLA degradation was observed for any of the salt solutions. Only after 14 days an amount of lactic acid ranging from 2 to $4 \%$ was found, reflecting a slight degradation of the polymer (Table 3). PLA NPs incubated with gastrointestinal fluids, serum or tissue homogenates for $48-60 \mathrm{~h}$ did not degrade since no traces of lactic acid were detectable. Thus, these results indicate that degradation was not an issue. Moreover, since diffusion decreases with increasing molecular weight (Masaro and Zhu 1999), dye diffusion from NPs was negligible on account of the high molecular weight of the probes used. As a further argument, an order of magnitude calculation allows to estimate the time needed for such a diffusion to occur. Considering the particle size $d=100 \mathrm{~nm}$ and the diffusion coefficient of the dye assumed comparable to a hydrophobic drug and equal to $10-20 \mathrm{~m}^{2} / \mathrm{s}$ (Polakovic et al. 1999), one can calculate an approximate characteristic time of diffusion equal to $10^{6} \mathrm{~s}$, which is by far higher than the time of analysis considered $\left(10^{5} \mathrm{~s}\right)$.

As shown in Fig. 3, the FI signals remained stable over the whole analysis for all fluids except for the PLA NPs incubated with gastric juice and spleen homogenate (Fig. 3c, e), where the FI signal decreased with time. FI changes occurred only in biological samples where DLS already showed aggregation. Thus, it can be concluded that dye diffusion was indeed negligible, since otherwise the FI signal would have increased with time, and that the signal drop was due to quenching consequent to particle aggregation. Hence, there is a correlation between the information on suspension stability provided by DLS and the FI analysis.

Figure 3c, e shows that the FI signal drops $30 \%$ after approximately 22 and $12 \mathrm{~h}$, respectively. These 


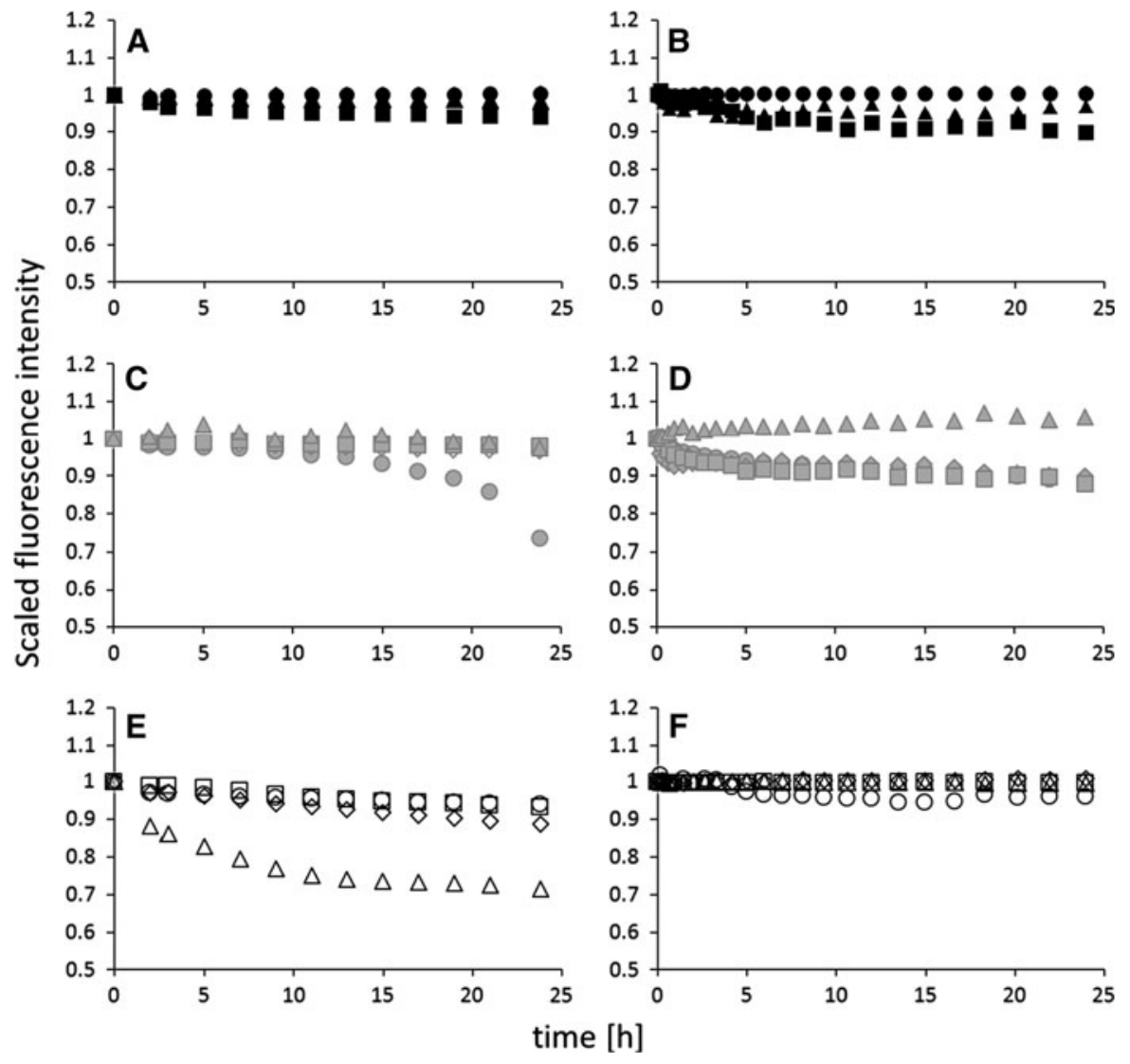

Fig. 3 Effect of biological fluids on NP stability-FI measurements. Stock solutions: distilled water (filled diamond), PBS (filled square), isotonic (filled triangle), dextrose (filled circle); gastrointestinal fluids: Synthetic intestinal fluid (shaded

are roughly the times of the start of aggregation established by DLS (Fig. 2c, e). Far from providing a quantitative correlation, these findings do confirm a qualitative accordance between the techniques and thus the possibility of using spectrophotofluorimetry to verify NP stability in ex vivo samples.

\section{Conclusions}

To design effective polymeric NPs for drug delivery, their stability has to be assessed thoroughly not only in stock solutions but also in fluids mimicking biological ones and in organ homogenates. Colloidal stability and polymer degradation of NPs in synthetic gastrointestinal fluids, serum and tissue homogenates was evaluated for $48-60 \mathrm{~h}$, to reproduce their typical time of persistence in the body, and up to $200 \mathrm{~h}$ in stock diamond), artificial lysosomal fluid (shaded square), saliva (shaded triangle), gastric juice (shaded circle); homogenates: serum (open diamond), brain (open square), spleen (open triangle), liver (open circle)

solutions. While PMMA NPs remained stable in all the fluids, PLA NPs aggregated in gastric juice and in spleen homogenate.

These data also indicate that DLS is a powerful tool to evaluate NP colloidal stability in vitro/ex vivo experiments and that SPF analysis can be used to assess the stability as well. Qualitative accordance was found between DLS and spectrophotofluorimetry proving that this latter technique can indeed be used when switching from in vitro to ex vivo analysis to overcome opacity of the biological samples. These stability evaluation procedures should be therefore adopted for any new NP formulation before attempting in vivo studies.

Acknowledgments This study was partly funded by the Telethon Foundation, Project n. GGP 10120, by the European Community's Seventh Framework Program (FP7/2007-2013) under grant agreement n. 212043 and by AIRC-Associazione 
Italiana per la Ricerca sul Cancro, Special Program Molecular Clinical Oncology 5 per mille, Project n. 10016. All these funders have not roles in the study design and in the decision to submit the paper for publication. The authors acknowledge the support by the Electron Microscopy of ETH Zurich (EMEZ). Furthermore they thank Marco Furlan for taking the TEM pictures.

Conflict of interest All authors disclose any actual or potential conflict of interest including any financial, personal or other relationships with other people or organizations within 3 years of beginning the work submitted that could inappropriately influence (bias) their work.

\section{References}

Aggarwal P, Hall JB, McLeland CB, Dobrovolskaia MA, McNeil SE (2009) Nanoparticle interaction with plasma proteins as it relates to particle biodistribution, biocompatibility and therapeutic efficacy. Adv Drug Deliv Rev 61(6):428-437. doi:10.1016/j.addr.2009.03.009

Alexis F, Pridgen E, Molnar LK, Farokhzad OC (2008) Factors affecting the clearance and biodistribution of polymeric nanoparticles. Mol Pharm 5(4):505-515. doi:10.1021/ mp800051m

Arifin DY, Lee LY, Wang CH (2006) Mathematical modeling and simulation of drug release from microspheres: Implications to drug delivery systems. Adv Drug Deliv Rev 58(12-13):1274-1325. doi:10.1016/j.addr.2006.09.007

Avgoustakis K, Beletsi A, Panagi Z, Klepetsanis P, Karydas AG, Ithakissios DS (2002) PLGA-mPEG nanoparticles of cisplatin: in vitro nanoparticle degradation, in vitro drug release and in vivo drug residence in blood properties. J Control Release 79(1-3):123-135

Codari F, Moscatelli D, Storti G, Morbidelli M (2010) Characterization of low-molecular-weight PLA using HPLC. Macromol Mater Eng 295(1):58-66. doi:10.1002/mame. 200900172

Cui F, Qian F, Zhao Z, Yin L, Tang C, Yin C (2009) Preparation, characterization, and oral delivery of insulin loaded carboxylated chitosan grafted poly(methyl methacrylate) nanoparticles. Biomacromolecules 10(5):1253-1258. doi: 10.1021/bm900035u

Devalapally H, Chakilam A, Amiji MM (2007) Role of nanotechnology in pharmaceutical product development. J Pharm Sci 96(10):2547-2565. doi:10.1002/jps.20875

Fessi H, Puisieux F, Devissaguet JP, Ammoury N, Benita S (1989) Nanocapsule formation by interfacial polymer deposition following solvent displacement. Int $\mathbf{J}$ Pharm 55(1):R1-R4

He CB, Hu YP, Yin LC, Tang C, Yin CH (2010) Effects of particle size and surface charge on cellular uptake and biodistribution of polymeric nanoparticles. Biomaterials 31(13):3657-3666. doi:10.1016/j.biomaterials.2010.01. 065

Kuentz M (2008) Drug absorption modeling as a tool to define the strategy in clinical formulation development. AAPS J 10(3):473-479. doi:10.1208/s12248-008-9054-3
Kumari A, Yadav SK, Yadav SC (2010) Biodegradable polymeric nanoparticles based drug delivery systems. Colloids Surf B 75(1):1-18. doi:10.1016/j.colsurfb.2009.09.001

Lemoine D, Francois C, Kedzierewicz F, Preat V, Hoffman M, Maincent P (1996) Stability study of nanoparticles of poly(epsilon-caprolactone), poly(D,L-lactide) and poly(D,Llactide-co-glycolide). Biomaterials 17(22):2191-2197

Liu Y, Cheng CY, Prud'homme RK, Fox RO (2008) Mixing in a multi-inlet vortex mixer (MIVM) for flash nano-precipitation. Chem Eng Sci 63(11):2829-2842. doi:10.1016/ j.ces.2007.10.020

Madlova M, Jones SA, Zwerschke I, Ma Y, Hider RC, Forbes B (2009) Poly(vinyl alcohol) nanoparticle stability in biological media and uptake in respiratory epithelial cell layers in vitro. Eur J Pharm Biopharm 72(2):437-443

Masaro L, Zhu XX (1999) Physical models of diffusion for polymer solutions, gels and solids. Prog Polym Sci 24(5): 731-775

Mohs AM, Duan HW, Kairdolf BA, Smith AM, Nie SM (2009) Proton-resistant quantum dots: stability in gastrointestinal fluids and implications for oral delivery of nanoparticle agents. Nano Res 2(6):500-508. doi:10.1007/s12274009-9046-3

Mora-Huertas CE, Fessi H, Elaissari A (2010) Polymer-based nanocapsules for drug delivery. Int $\mathbf{J}$ Pharm 385(1-2): 113-142. doi:10.1016/j.ijpharm.2009.10.018

Muthu MS, Feng SS (2009) Pharmaceutical stability aspects of nanomedicines. Nanomedicine (Lond) 4(8):857-860. doi: $10.2217 / \mathrm{nnm} .09 .75$

Oh JK (2011) Polylactide (PLA)-based amphiphilic block copolymers: synthesis, self-assembly, and biomedical applications. Soft Matter 7(11):5096-5108. doi:10.1039/ c0sm01539c

Polakovic M, Gorner T, Gref R, Dellacherie E (1999) Lidocaine loaded biodegradable nanospheres II. Modelling of drug release. J Control Release 60(2-3):169-177. doi:10.1016/ s0168-3659(99)00012-7

Prokop A, Davidson JM (2008) Nanovehicular intracellular delivery systems. J Pharm Sci 97(9):3518-3590. doi: 10.1002/jps. 21270

Riehemann K, Schneider SW, Luger TA, Godin B, Ferrari M, Fuchs H (2009) Nanomedicine-challenge and perspectives. Angew Chem Int Edn 48(5):872-897. doi:10.1002/ anie. 200802585

Rizzardini M, Zappone M, Villa P, Gnocchi P, Sironi M, Diomede L, Meazza C, Monshouwer M, Cantoni L (1998) Kupffer cell depletion partially prevents hepatic heme oxygenase 1 messenger RNA accumulation in systemic inflammation in mice: role of interleukin 1beta. Hepatology 27(3):703-710. doi:10.1002/hep.510270311

Ruenraroengsak P, Cook JM, Florence AT (2010) Nanosystem drug targeting: facing up to complex realities. J Control Release 141(3):265-276. doi:10.1016/j.jconrel.2009.10. 032

Squire MW, Ludwig BJ, Thompson JR, Jagodzinski J, Hall D, Andes D (2008) Premixed antibiotic bone cement-an in vitro comparison of antimicrobial efficacy. J Arthroplast 23(6):110-114. doi:10.1016/j.arth.2008.03.014

von Burkersroda F, Schedl L, Gopferich A (2002) Why degradable polymers undergo surface erosion or bulk erosion. Biomaterials 23(21):4221-4231 
Win KY, Feng SS (2005) Effects of particle size and surface coating on cellular uptake of polymeric nanoparticles for oral delivery of anticancer drugs. Biomaterials 26(15): 2713-2722. doi:10.1016/j.biomaterials.2004.07.050
Yu YC, Storti G, Morbidelli M (2009) Ring-opening polymerization of L,L-lactide: kinetic and modeling study. Macromolecules 42(21):8187-8197. doi:10.1021/ma901359x 